
\title{
\& Research Square \\ Exploring the Consequences of Early Marriage among Kurdish Women: A Qualitative Study in Western Iran
}

\section{Mahnaz Solhi}

Iran University of Medical Sciences

\section{Farbod Ebadi Fard Azar}

Iran University of Medical Sciences

\section{Farideh Khalajabadi Farahani}

Tehran University of Medical Sciences

Javad Yoosefi Lebni ( $\nabla$ j.yousefi28@yahoo.com )

Iran University of Medical Sciences School of Behavioral Sciences and Mental Health https://orcid.org/0000-0002-9612-9145

\section{Research article}

Keywords: Early Marriage, Consequences, Kurdish Women, Iran, Qualitative Study

Posted Date: August 25th, 2020

DOl: https://doi.org/10.21203/rs.3.rs-55314/v1

License: (c) (i) This work is licensed under a Creative Commons Attribution 4.0 International License. Read Full License 


\section{Abstract}

Background: Early marriage is one of the most important social issues for young women, which can have many consequences, so this study was conducted to explain the consequences of early marriage among Kurdish women in western Iran.

Methods: This qualitative study was conducted with the approach of conventional content analysis among Iranian Kurdish women who were married under the age 18. The data were saturated through semi-structured interviews with 30 women selected by purposeful sampling. Data analysis was performed by Graneheim and Lundman method.

Results: 389 codes, 14 subcategories, 4 sub-categories and 2 main categories were extracted from data analysis. Negative consequences of early marriage include 1- Physical and psychological problems (highrisk pregnancy and childbirth, physical illnesses, yearning and remorse, psychological challenges) 2Family problems (experience of violence, dissatisfaction with married life, experience of multiple roles, lack of independence in Family life) 3. Social problems (social deviance, deprivation of social and health services, social isolation, deprivation of job and educational opportunities) and positive consequences include receiving intra- family support, improving living conditions and opportunities for progress and empowerment.

Conclusions: It is possible to reduce the negative consequences of early marriage through teaching young women to have a less dangerous pregnancy and childbirth, training and using psychological counseling on how to deal with personal problems and married life, and providing appropriate social and health services for them.

\section{Background}

In the last three decades, national and international organizations have paid more attention to children's rights[1]. One of the violations of children's rights is child marriage[2], which refers to marriage under the age of 18[3] and although it can have devastating consequences for both genders, it is considered as one of the examples of gender discrimination because it does more harm to girls[4]. It is estimated that girls marry almost five times more than boys under the age of 18, and about 250 million of them marry before the age of 13[3]. The rate of child marriage varies from country to country, Africa and Western Europe having the highest and lowest rates, respectively[5].

In Iran, the minimum legal age for marriage is 13 for girls, but men can make girls under the age of 13 married with a judge's order[6]. The rate of child marriage in rural areas of Iran is reported as 19.6 and in urban areas as 13.7[7]. In the first 9 months of 2016 in Iran, 13820 cases of marriage under the age of 18 have been registered while child marriage figures appear to be higher than official figures because many child marriages take place unofficially in families and are not officially registered [8]. 
Child marriage occurs for reasons such as cultural beliefs[9], social norms[10], poverty[11], family[7], control of girls[12] and religion[13].

Child marriage is fraught with devastating consequences. In a study, child marriage was significantly associated with non-use of contraceptives before the first delivery, high fertility (three or more births) and repeated pregnancy in less than three months and multiple unwanted pregnancies[14]. The study by Nasrullah et al, 2014, entitled Child Marriage and Its Associations With Controlling Behaviors and Spousal Violence Against Adolescent and Young Women in Pakistan, found that women who married as children experienced more behavioral control than adult women. They also experienced more domestic violence, including various forms of physical and emotional violence[15]. Irani \& Latifnejad Roudsari, 2019 also showed in a review study that child marriage in girls is associated with the consequences of death during childbirth, physical and sexual violence, depression, risk of getting sexually transmitted diseases and preterm birth[16]. A qualitative study conducted by Mardi et al. in 2018 in Ardabil, Iran, showed that adolescent women confront experiences such as misunderstanding of sexual relations, death of dreams and threatened independence. Also, the results of their study showed that adolescent women cannot understand life opportunities, and health care providers and policymakers need to make adolescents aware of the negative consequences of early marriage and prevent them from doing it[17].

In Iran, few qualitative studies have been conducted on the consequences of child marriage and none of the studies have been conducted in the study areas. Since the study population is different in terms of ethnicity, language and culture from other parts of Iran and according to the experiences of the first author of the article, who has been researching women in this area for many years, it seems that a separate study should qualitatively examine the consequences of early marriage in this region. Therefore, the aim of the present study was to explain the consequences of early marriage among Kurdish women in western Iran with a qualitative approach.

\section{Methods}

This study is a qualitative research conducted by conventional content analysis method[18]. The study population consisted of married women who had married under the age of 18 . The criteria for entering the study included: marriage experience under the age of 18, being under 25 at the time of study, living in two Kurdish provinces of Kermanshah and Kurdistan at the time of marriage and this research and willingness to participate in research.

In this study, purposeful sampling method was used to select samples that provide the most information to researchers. After receiving the code of ethics (IR.IUMS.REC.1397.1225) from Iran University of Medical Sciences, the researchers went to the health centers of the cities and villages under study and asked them to introduce the women who had the criteria to enter the study. Having the address of the place of residence, the researchers went to the people's house and invited them to participate in the research by stating the goals and necessity of the research. 
The information needed for the study was obtained through semi-structured face-to-face interviews. The interviews were conducted by the first author of the article, who is a PhD student in health education and health promotion and lives in the study area and has a background in qualitative research in the field of women, as well as a trained woman with MA degree in women's studies who was familiar with qualitative method. Note taking was done during the interviews. At the beginning of each interview, the researchers, who had the necessary skills to conduct qualitative research, in addition to stating the goals and necessity of the study, provided a brief description of their scientific resume. Then the interview started with a few questions about demographic characteristics such as age and education, and continued with questions like "As someone who had an early marriage, what experiences do you have of this phenomenon? What changes did early marriage make in your personal, family, and social life? What positive effects has early marriage had on your life?" It then ended with short complementary questions to get the depth and breadth of the answers. The place and time of the interview were determined by the participants, mostly in places such as their homes, libraries and cultural places, as well as parks and public places. The duration of the interviews varied for each participant, but average time was 68 minutes. All interviews were conducted in the local Kurdish language and then translated by the first author, who was proficient in Persian.

The researchers stopped the interview when conceptual saturation occurred, and data saturation occurs when no new data are obtained from the interview[19]. Conceptual saturation occurred in interview 23 when the codes were repetitive, but the researchers conducted seven more interviews to reach greater confidence and to prevent false saturation, reaching 30 people. Data collection and analysis began in July 2019 and ended on April $13^{\text {th }}, 2020$.

The data analysis process was performed using the 5 steps suggested by Graneheim \& Lundman[18]. In the first step, the corresponding and first author of article listened to all the interviews that were recorded, once individually and the other time together. Then they typed all the interviews in Word software. In the second step, the text of the interviews was read several times to gain an understanding of the whole text. In the third step, the texts were read word by word and the codes were retrieved. The open codes were then categorized under more general headings. In the fourth step, the codes were categorized into categories based on their similarities and differences, and how they were related was determined. In the last step, the data were placed in the main categories, which were more abstract and more conceptual. The analysis of the data was done manually and all the authors of the article monitored the process and expressed their views in separate meetings.

In order to observe the ethical issues of the research, all participants and spouses of women under the age of 18 signed a written consent form before the interview, and written consent was obtained to record the interviews. Participants were also assured that their names and address will remain confidential and the code will be used to name them during the research process, and at the end they were given the freedom to postpone the interview to another time and place wherever they wanted or cut it completely. The study was approved by the Ethics Committee of Iran University of Medical Sciences, with code IR.IUMS.REC.1397.1225. 
To confirm the validity and rigor of the study, the researchers used the Guba and Lincoln criteria[20]. To gain credibility in this study, firstly participants were selected who had the most diversity in terms of socioeconomic characteristics. Then the findings were given to 8 participants and they expressed their views on the matching of the findings to their experiences of early marriage. In addition, because the researchers were natives of the study areas and had the experience of qualitative research on Kurdish women, they could easily communicate with participants and obtain good information from them. To gain confirmability, the researchers sent the data analysis process to four people who were familiar with the principles of qualitative research and had experience in researching child marriage, and their supplementary feedback was used. To gain dependability, all the authors of the article participated in the process of analysis and coding, and the opinions of all members of the research team were used. Also, in order to obtain the transferability, in addition to presenting many direct quotes from the participants, a detailed description of the whole research process was provided. The results of the study were also given to four women who had similar characteristics to the participants in the project but did not participate in the study, and they were asked to state whether they agreed with the research results, and whether they had experiences similar to the experiences of participants in this study. They accepted the results of the study.

\section{Results}

The study ended with the participation of 30 women whose demographic characteristics are shown in Table 1. After analyzing the data, 389 open codes, 14 subcategories, 4 categories and 2 main categories were extracted, which are described below (Table 2).

Table1. Demographic characteristics of participants 


\begin{tabular}{|c|c|c|}
\hline Variable & Dimension & Frequency (\%) \\
\hline \multirow{3}{*}{ Age } & $<16$ & $6(30)$ \\
\hline & $16-20$ & $16(53.33)$ \\
\hline & $20-25$ & $8(26.66)$ \\
\hline \multirow{4}{*}{ Education } & illiterate & $4(13.33)$ \\
\hline & Under diploma & $14(46.66)$ \\
\hline & diploma & $8(26.66)$ \\
\hline & Higher than diploma & $4(13.33)$ \\
\hline \multirow{2}{*}{ Residence } & Urban & $11(36.66)$ \\
\hline & Rural & $19(63.33)$ \\
\hline \multirow{3}{*}{ The age of first marriage } & $<15$ & $7(23.33)$ \\
\hline & $15-16$ & $10(33.33)$ \\
\hline & $16-18$ & $13(43.33)$ \\
\hline \multirow{3}{*}{ Type of marriage } & Forced & $10(33.33)$ \\
\hline & traditional & $12(40)$ \\
\hline & Self-choice & $8(26.66)$ \\
\hline \multirow[t]{3}{*}{ Age difference with spouse } & $<5$ & $7(23.33)$ \\
\hline & $5-10$ & $13(43.33)$ \\
\hline & $>10$ & $10(33.33)$ \\
\hline \multirow[t]{2}{*}{ Abortion background } & Yes & $11(36.66)$ \\
\hline & No & $19(63.33)$ \\
\hline
\end{tabular}

Table2. Main categories, categories, subcategories and codes extracted from the analysis of interviews 


\begin{tabular}{|c|c|c|c|}
\hline $\begin{array}{c}\text { Main } \\
\text { categories }\end{array}$ & Categories & Subcategories & Codes \\
\hline \multirow[t]{11}{*}{$\begin{array}{l}\text { Negative } \\
\text { consequences }\end{array}$} & \multirow{4}{*}{$\begin{array}{l}\text { Individual } \\
\text { physical and } \\
\text { psychological } \\
\text { problems }\end{array}$} & $\begin{array}{l}\text { high-risk } \\
\text { pregnancies } \\
\text { and childbirths }\end{array}$ & $\begin{array}{l}\text { unwanted pregnancy, unawareness of how to control } \\
\text { fertility, infant mortality, increase of abortion risk, } \\
\text { recurrent abortion, abnormal delivery, postpartum } \\
\text { hemorrhage, and short interval between births }\end{array}$ \\
\hline & & $\begin{array}{l}\text { physical } \\
\text { illnesses }\end{array}$ & $\begin{array}{c}\text { blood pressure, underweight, severe headaches, food } \\
\text { shortage, delayed physical growth, iron deficiency and } \\
\text { backache }\end{array}$ \\
\hline & & $\begin{array}{l}\text { yearning and } \\
\text { remorse }\end{array}$ & $\begin{array}{l}\text { yearning for childhood, yearning for adolescence, yearning } \\
\text { for love, yearning for studying, remorse for early marriage } \\
\text { and remorse for early pregnancy }\end{array}$ \\
\hline & & $\begin{array}{l}\text { psychological } \\
\text { challenges }\end{array}$ & $\begin{array}{l}\text { depression, suicide ideation and attempt, feelings of } \\
\text { inferiority and low self-confidence }\end{array}$ \\
\hline & \multirow{4}{*}{$\begin{array}{c}\text { Family } \\
\text { problems }\end{array}$} & $\begin{array}{l}\text { Experience of } \\
\text { violence }\end{array}$ & economic, physical, psychological, and sexual violence \\
\hline & & $\begin{array}{l}\text { Dissatisfaction } \\
\text { with married } \\
\text { life } \\
\end{array}$ & emotional divorce, divorce and sexual dissatisfaction \\
\hline & & $\begin{array}{l}\text { Experience of } \\
\text { multiple roles }\end{array}$ & $\begin{array}{l}\text { role of child-wife, mother-child, and bride-child, being the } \\
\text { head of the household, staying in the role of child and being } \\
\text { thrown into the adult world }\end{array}$ \\
\hline & & $\begin{array}{l}\text { Lack of } \\
\text { independence } \\
\text { in family life }\end{array}$ & $\begin{array}{c}\text { powerlessness in decisions for home, powerlessness in } \\
\text { decisions for children, and powerlessness in determining } \\
\text { family relationships }\end{array}$ \\
\hline & \multirow[t]{3}{*}{$\begin{array}{c}\text { Social } \\
\text { problems }\end{array}$} & $\begin{array}{c}\text { Social } \\
\text { deviance }\end{array}$ & $\begin{array}{c}\text { having an emotional / sexual relationship outside the } \\
\text { family, a desire to run away from home, and a desire to } \\
\text { drink alcohol and smoking }\end{array}$ \\
\hline & & $\begin{array}{l}\text { Deprivation of } \\
\text { social and } \\
\text { health } \\
\text { services }\end{array}$ & $\begin{array}{c}\text { lack of access to necessary health services, lack of access } \\
\text { to social services such as counseling centers, lack of social } \\
\text { support in society, deprivation of the media and low } \\
\text { knowledge of technology }\end{array}$ \\
\hline & & & $\begin{array}{c}\text { leaving relationships with peers, being locked up at home, } \\
\text { interacting with people who are incompatible in terms of } \\
\text { age etc. }\end{array}$ \\
\hline
\end{tabular}




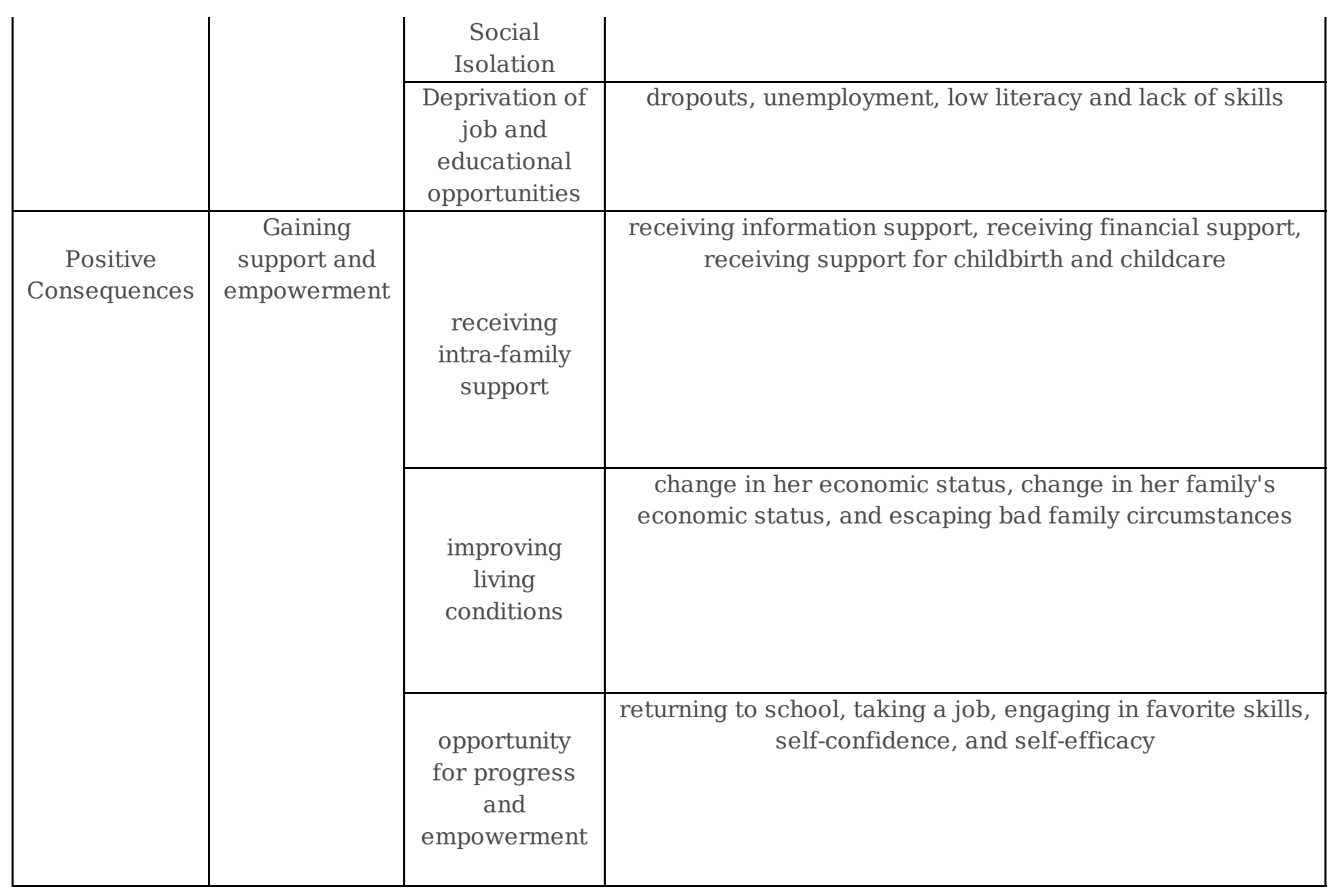

Negative Consequences of Early Marriage: Early marriage posed many challenges for women at various individual, family, and social levels, leading most participants to regret for the marriage.

1- Individual physical and psychological problems: Marriage in childhood endangers women's personal health and makes them confront with more physical and psychological problems such as high-risk pregnancies and childbirths, physical illnesses, yearning and remorse, and psychological challenges.

High-risk pregnancies and childbirths: It consists of codes such as unwanted pregnancy, unawareness of how to control fertility, infant mortality, increase of abortion risk, recurrent abortion, abnormal delivery, postpartum hemorrhage, and short interval between births.

"Honestly, I didn't want to get pregnant, but I didn't know how to prevent it. There was no one to guide me. I got pregnant very soon." (Participant, 5)

"I have had two abortions. Most of those who get married at a young age have such an experience." (Participant, 14)

"I really wanted to give birth naturally, but I couldn't give birth to my baby, so I had a cesarean section." (Participant, 28) 
"For the first four years of my life, I was pregnant all the time and my baby was not born alive. My body had nothing left." (Participant, 17)

"I became very weak after childbirth and I had a lot of problems." (Participant, 30$)$

Since adolescent women do not have the proper knowledge and skills of contraception, they usually become pregnant unwantedly and soon after marriage, and because they are not physically and mentally ready for childbirth, they face many problems so that she endangers the health of herself and her children, and it may even lead to the death of both..

Having physical illnesses: This subcategory includes the codes of blood pressure, underweight, severe headaches, food shortage, delayed physical growth, iron deficiency and backache.

"I had my first abortion then I had a nosebleed two months later. I went to the doctor. They told me that my blood pressure had gone up. Every once in a while, my blood pressure rises and it bothers me." (Participant, 4)

"I don't know, maybe I'm wrong, but I feel like marriage made me have a severe headache. I went to a doctor and he said I had a migraine." (Participant, 10)

"I'm young, but every part of my body is in pain. Sometimes my backache drives me crazy." (Participant, 18)

Girls who get married as children have many physical problems after marriage that can endanger their health and lower their quality of life.

Yearning and remorse: This subcategory includes the codes of yearning for childhood, yearning for adolescence, yearning for love, yearning for studying, remorse for early marriage and remorse for early pregnancy.

"I have always yearned the childhood that I never had. I always wanted to ride a bike, but they gave me to marriage early. After marriage, if you ride a bike, everyone will blame you." (Participant, 20)

"When I see some of my friends got married with love and affection my heart breaks, I feel very sorry that I wish I had fallen in love. It's annoying that I can't experience love anymore." (Participant, 30)

"The fact that I didn't study and don't have a job is the biggest regret of my life. If I go back in time, I would never get married soon." (Participant, 6)

"I cry when I hear from some people that the best experiences of their lives are marriage and having children, because it has been the worst experience of my life, because for none of them I had love and heartfelt desire." (Participant, 3) 
"I regret when I thought I could enjoy my marriage and having children, but because of my early marriage, everything was ruined." (Participant, 1)

Child marriage prevents a child from experiencing childhood and adolescence like their peers, and this annoys them in the future, and in the case of marriage and pregnancy, which can be a woman's sweetest experiences, early marriage makes them the worst happenings in life. These issues can cause girls who have been married as children to face a lot of yearnings and regrets. Also, when they see their successful peers who have been educated and have a job, they inevitably compare it with their lives and circumstances, and have more regret.

Psychological Challenges: This subcategory consists of the codes of depression, suicide ideation and attempt, feelings of inferiority and low self-confidence.

"I haven't laughed from bottom of my heart for a long time. I'm always sad why I got married so soon. I'm not in the mood for anyone. My sister tells me I'm depressed." (Participant, 12)

"I have decided several times to kill myself and get rid of this life. Once I poured oil on myself, but as soon as I lit the fire, my brother-in-law understood and did not let me kill myself." (Participant, 12)

"My self-confidence is very low. I feel worthless. I don't like to be with others at all. When I want to talk, I mispronounce some words." (Participant, 20)

Child marriage puts a lot of pressure on women and causes them a lot of psychological problems, and because they have no skills or abilities to solve these problems, it lowers their self-confidence and increases their feelings of inferiority, which leads to depression, and in the end, it can even lead to suicide.

2 - Family problems: Families that are formed by the child marriage are more fragile than other families due to their circumstances and face many problems that in some cases these problems can eradicate the foundation of the family.

Experience of violence: This subcategory includes codes of economic, physical, psychological, and sexual violence. Many participants reported experiencing a variety of types of violence.

"I'm not financially independent. Every time I ask my husband for money, he annoys me a lot to give me money. Sometimes he forces me to stop another request for the money he gives me." (Participant, 14)

"It's been less than two months since our marriage, my husband gave me a beating. He is very violent. He often beats me for trivial things. "(Participant, 15)

"I've heard a lot of insults from my husband. He says a lot of ugly things to me. Sometimes he yells at me in the family gathering and says ugly things to me." (Participant, 1 )

"I didn't know much about sex in the beginning, so I didn't know how to please my husband. My husband sometimes got angry and told me I didn't know anything and he would do whatever he wanted, even if I 
wasn't happy." (Participant, 8)

"I was very annoyed the first night and that's why I never enjoy sex anymore. Every time we do this, I get more annoyed. My sister, who got married early, says like me, she doesn't enjoy it at all." (Participant, 25)

Girls who marry as children have less awareness, skills, and power in life, as well as less knowledge of social rights, sexual issues, and married life. Thus they are abused by their husbands. Also, because they grew up in a traditional society where talking about sex has always been a taboo and they have not been properly familiar with sex in the education system, they do not have a proper understanding of sex and cannot meet the needs of their husbands. Therefore, they are sexually abused and may even suffer severe injuries.

Dissatisfaction with married life: The codes of emotional divorce, divorce and sexual dissatisfaction are related to this subcategory. Most women said they did not have a desired married life, which in some cases led to divorce, and in cases that still there was life emotional divorce and sexual dissatisfaction were seen.

"My husband and I don't understand each other at all. Sometimes we don't talk for ten minutes all week. If it weren't for my baby, I would separate." (Participant, 23)

"I had a disagreement and argument with my husband from the very beginning of my life. He said "you don't know anything". Our life wasn't good at all. We fought with each other all the time and I had to divorce him." (Participant, 12)

"My husband and I have large age difference, so we can't satisfy each other sexually." (Participant, 6)

Some of the participants got married by force or due to poor social and economic conditions and without love and interest, and had a big age difference with their husbands, so they experienced many problems in life and were not satisfied with their married life.

Experience of multiple roles: The role of child-wife, mother-child, and bride-child, being the head of the household, staying in the role of child and being thrown into the adult world were among the codes of this subcategory. Many women, although still children, had to take on multiple roles at the same time, which put a lot of pressure on them.

"When I got married, I was very young. I used to watch cartoons in my father-in-law's house. My husband argued with me many times about this. He said, 'Why are you behaving like this? You grew up. You mustn't watch cartoon.' "(Participant, 26)

"We lived with my husband's family. They expected me to behave like a perfect woman, but I didn't know many things. Whenever they had guests, after guest went they would argue with me a lot, saying my behavior was wrong." (Participant, 2) 
"When my husband died, I was 17 years old and had a two-month-old baby. I had to be both a father and a mother to my child while I was still a child." (Participant, 4)

"It wasn't until a month after we got married that I realized I was pregnant. I got confused; I didn't know what to do. I was just crying. I was a child myself. When my baby was born, I couldn't protect her at all." (Participant, 23)

"I was a child myself, but I was expected to be both a good wife and a good mother. No one understood me." (Participant, 29)

"I feel like I didn't have adolescence and youngness. As soon as I came to my senses I saw that I was thrown out of my childhood world into the adult world. I didn't understand anything as a teenager and a young person, and that bothers me." (Participant, 1)

With early marriage, children are forced to take on several different roles at the same time. Each of these roles has its own expectations, and because they have not been trained for any of these roles, they are not prepared, so they are under a lot of pressure.

Lack of independence in family life: This subcategory consists of codes of powerlessness in decisions for home, powerlessness in decisions for children, and powerlessness in determining family relationships.

"My husband makes his decisions without telling me anything. He hasn't asked my opinion at all." (Participant, 8)

"My mother-in-law makes a lot of decisions for me. She says "You are very young. You don't have much experience". (Participant, 4)

"I can't even wear my favorite clothes; I didn't want to have children at all, but my husband's family kept on me about it so I had to do it." (Participant, 2)

"When you get married as a child, everyone likes to interfere in your life because they think you don't understand anything of life." (Participant, 30)

"I wanted to name my daughter as I like, but my husband and his family chose something else. They didn't ask me if I like this name or not." (Participant, 18)

Child marriage makes girls be more vulnerable in their married life and have less power of bargaining and negotiation to advance their goals. There should also be space for others to interfere, as adults think that the young bride does not have enough experience and should be trained to live, so they allow themselves to interfere in their most personal matters.

3- Social problems: In addition to individual and family problems, young women also face problems and limitations in the society that can make living conditions more difficult for them. 
Social deviance: This subcategory includes the codes of having an emotional / sexual relationship outside the family, a desire to run away from home, and a desire to drink alcohol and smoking.

I'm 22 years younger than my husband. We don't understand each other at all. I often go on social networks and talk with other people." (Participant, 17)

"For the first few years of my life, I just cried. My husband is a smoker. I started smoking, firstly he disagreed but then he didn't say anything to me." (Participant, 2)

"In order to think less about my life and grieve less, I sometimes drink. We always have it in the fridge, my husband drinks a lot." (Participant, 14)

Marriage in childhood causes many problems for girls. In some cases, these girls are drawn to social deviance to get rid of these conditions or to endure them.

Deprivation of social and health services: This subcategory consists of the codes of lack of access to necessary health services, lack of access to social services such as counseling centers, lack of social support in society, deprivation of the media and low knowledge of technology.

"When I got married, I didn't know many things. There was no special place for me to ask for their help and advice." (Participant, 11)

"I studied until the third grade of elementary school. I don't know much about education. I can't even work with new phones. I don't know anything about the Internet, too." (Participant, 15)

"I and all those who get married at a really young age have our own special needs, but there is no special place for us." (Participant, 29)

Despite many social and health needs of girls who have experienced early marriage, there is no institution or organization in the society to support these girls and no special training and privileges are provided for them. Lack of sufficient literacy and media skills and abilities is another problem for these women, which makes them not even know how to find the answers to their questions.

Social Isolation: This subcategory includes the codes of leaving relationships with peers, being locked up at home, and interacting with people who are incompatible in terms of age etc.

"When I got married, I cut off most of my school friends. I had nobody left. I felt very bad." (Participant, 6)

"My husband doesn't like me to be in a relationship with my single friends. I had nobody left to confide in." (Participant, 20)

"In my husband's relatives, those who are married are all too old and I cannot be intimate with single people. That's why I have more relationships with people who are older than me. We cannot understand 
each other. I hate having to deal with people who are older than me and we don't understand each other. " (Participant, 17)

"After marriage, I had to stay at home all the time. My husband is the driver of a big truck. He is at home no more than 4-5 days. When he leaves, I have to stay home. Because he dislikes I go somewhere alone. " (Participant, 26)

Girls who marry early fall out of the world of their peers and are forced to have relationships with people who have large age difference with them. This makes them less inclined to have relationships with others, which in turn leads to more social isolation. Also, it is not culturally acceptable for married women to associate with single girls, so girls who have early marriages will soon be separated from their peers.

Deprivation of job and educational opportunities: This subcategory includes the codes of dropouts, unemployment, low literacy and lack of skills. Most participants stated that after marriage they were forced to drop out of school, or that they had studied for a short time, so they did not have the opportunity to learn a skill due to marrying early and getting busy with life and child care.

"I was 16 when I got married and then I had to drop out of school. My husband used to say, 'Why does a woman want to study!?' "(Participant, 2)

"I got married as a child. I didn't know anything. Now that I want to have a job, I don't have any skills. I wish I hadn't gotten married and I studied to be a person." (Participant,3)

"I was good at tailoring. I was learning dress designing with my aunt. My aunt always told me that I had the best talent, but when I got married, I could continue my work for a month or two. Then I knew that I was pregnant. I got busy with child care and quit my work. "(Participant, 19)

Many children are forced to drop out of school after marriage and are forced to stay housewives and have no financial independence because they are neither educated nor skilled.

Positive Consequences: Marriage in childhood is not only associated with negative consequences, but in some cases these marriages can be useful and improve the lives and health of young girls, or at least save them from the bad conditions of the paternal family.

1- Gaining support and empowerment: This category consists of subcategories of receiving intra-family support, improving living conditions and the opportunity for progress and empowerment.

Receiving intra-family support: This subcategory includes the codes of receiving information support, receiving financial support, receiving support for childbirth and childcare.

"I didn't know anything about married life, but my sister-in-law, who had an early marriage, explained everything to me before the wedding."(Participant, 13) 
"My husband and I were both very young, so my father helped us, and my husband's family didn't let us be under much pressure. They said, 'You're too young, we have to take care of you.' "(Participant, 16)

"When I told my mother-in-law that I was pregnant, she got very happy. She told me not to worry at all and she would take care of my baby herself. Indeed, it was as she said. She did everything related to my baby until my baby reached 3 years old. "(Participant, 9)

Because early marriage is accepted by parents in the study area, young couples are more supported by their families after marriage.

Improving living conditions: The codes of change in her economic status, change in her family's economic status, and escaping bad family circumstances fall into this subcategory.

"I lived in a poor family. When I got married, my situation changed a lot. I had things I couldn't even dream of. It's true that my husband is 10 years older than me, but I'm very happy with my life." (Participant, 7)

"My father was an addict and he sold drugs. Our house was always full of addicts. My uncle was always very worried that my father's friends would hurt me. That's why he took me for his son. He supported us a lot. We have the best life now. Maybe if I hadn't gotten married sooner, my life would have been ruined and I would have killed myself. "(Participant, 27)

In some cases, girls living in economically and socially disadvantaged families made significant changes to their lives with early marriage. Early marriage made it easier for them to achieve better conditions so this made them happy and satisfied.

Opportunities for progress and empowerment: This includes the codes of returning to school, taking a job, engaging in favorite skills, self-confidence, and self-efficacy.

"Before I got married, I dropped out of school. After marriage, my husband helped me study. He was the teacher of the village. My mother-in-law helped with the housework. That's why I spent most of my time studying. I was accepted in the entrance exam of university of medical sciences. Maybe if I hadn't gotten married, I wouldn't have thought about studying. "(Participant, 21)

"Before I got married, I really wanted to be a hairdresser, but my family didn't allow me. After marriage my husband took me to hairdressing courses. Now I have a hair salon and I am really happy with my life. " (Participant, 7)

"When my first child was born, I felt very good. I felt I grew up. I enjoyed a lot to see that I could take care of my kid. I did my best to take care of her in the best possible way. When all my husband's family members praised me, my self-confidence increased." (Participant, 22)

"My husband is a good person and helps me a lot to be someone for myself. When I finished my sewing class and got a shop, I felt good about myself. I feel like I can do anything well." (Participant, 21) 
"I really enjoy seeing everyone count on me and get help and advice from me in their work, especially when my husband's family or my family is complimenting me in front of others." (Participant, 13)

Some of the participants grew up in families that put a lot of restrictions on them and prevented them from doing what they loved to do, but by getting married, these restrictions were removed and they pursued their favorite interests and skills, and this issue has led to the flourishing of their talents. Some other women who were able to cope with life's problems after marriage also felt good, which made them more satisfied.

\section{Discussion}

The aim of this study was to explain the consequences of early marriage among Kurdish women in western Iran. The results showed that early marriage was associated with severe negative consequences that could jeopardize the future of women and their families, but in a limited number of cases, nearly a quarter of participants, early marriage had positive consequences for them. It had made positive differences in their lives.

One of the consequences of early marriage was physical and psychological problems at the individual level. Physical weakness and illness were one of the consequences of early marriage, which could be due to the fact that these women are married at a time when their bodies have not yet completed the growth process and they are not ready to face the stress of sexual intercourse, pregnancy and childbirth. The occurrence of physical problems among women who have early marriages has also been shown in previous studies[21]. In this regard, another physical consequence of early marriage was high-risk pregnancy and childbirth, which was repeatedly mentioned by women. This may also be due to incomplete pelvic growth and possibly synchronization of pregnancy and puberty development. These consequences have also been shown in previous studies[22, 23]. Adhikari et al. 2009 also found that women who married under the age of 18 had more unwanted pregnancies than other women[24]. Adolescent women do not have any understanding of marital relations and how to prevent early pregnancy after marriage, so they get pregnant very quickly without wanting to, and since neither their bodies are ready for such a pregnancy nor they are mentally ready to accept it, the process of pregnancy and childbirth becomes difficult and painful for them. This can endanger the health of the child and the mother, so that in some cases it can lead to multiple abortions. One of the main reasons for early pregnancy in these women is the low awareness and weak communication skills in these women and their husbands; therefore the need for continuous instruction before and after marriage to help these couples is becoming more apparent. Marriage education and telephone counseling can be one of the strategies to help women plan for pregnancy and childbirth in order to prevent their negative consequences.

Emotional and psychological problems were another consequence of early marriage, which were frequently mentioned by women participating in the study. Child marriage cause women to experience different periods of their lives, such as childhood, adolescence, etc., as well as important life events such 
as love, marriage, and pregnancy in a different and bitter way, and since they spend most of these periods of their lives by force and without satisfaction and awareness, they have different conditions from their peers, and this leads to a kind of yearning and remorse in them. Marriage in childhood also deprives girls of the opportunity to continue their education and employment. This has led to longing and regret for them, which bothers them. In this line, challenges such as depression, suicide ideation and attempt, feelings of inferiority and low self-confidence were other psychological problems at the individual level that were mentioned. A 2012 study by Uecker found that early marriage had a negative effect on women's mental health[25]. Research by John et al and Daraz et al also showed that women who experience early marriage have psychological problems such as stress, depression and anxiety[26, 27]. Many married women were unprepared to experience any of the realities of their lives and never received training on how to deal with them, which puts them under a lot of stress in the face of the realities of life. Failure to provide a proper response can lead to their suicide. In the 2019 Yoosefi Lebni et al study, conducted in the Kurdish regions of Iran (the study area of this study), forced marriage was one of the important determinants of women's self-immolation[28]. The 2013 Gage study also found a significant association between early marriage and suicide attempts[29]. This is one of the issues that require mental health intervention for couples who have early marriages.

Experiencing all kinds of violence was one of the family consequences of early marriage in this study, which could be due to the lack of anger management skills and other communication skills among young couples. In most studies that have examined the consequences of early marriage, violence has been described as an inseparable part of the consequences of child marriage[15, 30-32]. Dissatisfaction with married life was another family consequence of early marriage in this study, which consists of emotional divorce, divorce, and sexual dissatisfaction. The results of the study showed that married women are not very satisfied with married life. In some cases, they stated that they are forced to continue living, and if they have suitable conditions or they receive more support from their father's family, they will no longer be willing to continue the married life. In the 2018 Hajihasani \& Sim study conducted in Iran, women who had the experience of early marriage had low satisfaction with married life[8].

Emotional divorce was another consequence of early marriage in this study, which has been less discussed in previous studies and is one of the noticeable results in this study. Some women stated that they did not have a stable relationship with their husbands in their married life and that they were only physically together and did not have any emotional interactions with each other. Tilson \& Larsen, 2000, also reported that early marriage can lead to divorce[33]. This can also be due to the fact that early marriages are not based on real knowledge and interest and they occur mostly by force or due to irrelevant reasons.

The experience of multiple roles, while they have not yet completed childhood, was another family problem of early marriage. Most participants stated that they had some sort of identity conflict due to having multiple roles at the same time. These women are forced to take on the role of wife with early marriage while they are still children, and after having children, the role of mother is added, and since 
most of these women live with their husbands' families, they are forced to take on more roles, this puts a lot of pressure on them.

Lack of autonomy due to lack of awareness and lack of life knowledge and skills was another important consequence of early marriage in this study. The results showed that women who get married early have a weak position in family life and many life decisions are made by their husbands or even the husband's family. Research by Mardi et al also found that women who experienced early marriage were less independent in family life[17].

In response to these problems, some of the women's interactions and reactions were to turn to some highrisk behaviors to relieve and get rid of the above problems. Turning to social deviance such as relationships outside the family, the desire to run away from home, and the desire for alcohol and smoking were some of the social consequences of early marriage in this study. In this study, in contrast to previous research that studied the association of child marriage with prostitution and AIDS[34-36], there was no prostitution among any of the samples that can refer to the social and cultural conditions of the study area because most women of this study lived in small environments where everyone knows each other and cannot turn to prostitution. Of course, it should be noted that there were tendencies to run away from home and have an emotional relationship outside the family.

Deprivation of social and health services was one of the interesting findings in this study and added to previous research. While women who have the experience of early marriage have the greatest need for social and health services they benefit the least from these services. This may be because young women are not literate enough to use these services and may also be restricted by their husbands and unable to use them. Paul \& Chouhan, 2019, also reported in a study of Indian women that women who married under the age of 18 had less access to maternal health care than other women[37].

Deprivation of opportunities for education and employment was other finding of this study that led to social isolation in women with early marriage. A finding that is consistent with previous research[38, 39]. Most women who marry as a child are forced to drop out of school and have no chance of learning the job skills, which in turn makes them weak and fragile and may lead them to other problems. Beattie et al considers staying in school to be a way to prevent children from marrying and falling into the trap of prostitution[35]. Therefore, strategies and interventions should be provided to complete the education and training of women who marry early.

Although the negative consequences of early marriage outweighed the positive consequences, one of the important findings was that some women reported positive results for early marriages, and in contrast to previous studies that showed only negative consequences, this study revealed the fact that women's marriages in certain family contexts, such as parental addiction and poor family circumstances, have exceptionally improved women's condition, but this cannot be generalized and requires further investigation that when these outcomes are positive. One of the positive results was receiving more family support. Some young women said that after marriage, they were supported by their and their husband's families in issues such as sex and marriage, finance, and childcare. These supports are rooted 
in a cultural belief that gives the young bride more value and dignity, and in the community under study, having a young bride is considered an advantage, so families are more supportive of their young brides. The improvement of life conditions was another desirable consequence of early marriage. This finding adds to previous research that early marriage under certain conditions may have positive outcomes, but in total, negative outcomes outweigh the positive outcomes. Providing opportunities for progress and empowerment was another new and thought-provoking finding in this study that occurred in a limited number of cases. The results showed that early marriage changed the living conditions of some women in such a way that their talents flourished. In fact, with their marriage and the support of their husbands, the women who dropped out of school before marriage were able to return to school and to learn and develop their favorite skills. This caused them to have high self-confidence and self-efficacy. This finding could be a basis for future research on the conditions under which a woman's early marriage has positive consequences. What are the characteristics of the wives of these people who have been able to provide the ground for the educational and professional development of these women?

\section{Strengths and Limitations}

This research is one of the few studies that qualitatively examines the consequences of early marriage in Iran especially in Kurdish areas that have their own social and cultural context, so it can provide first-hand information for policy makers, social workers and activists in the field of children and women in order to have a proper plan to reduce the negative consequences of this phenomenon. Another strength of the present study was that the researcher (the first author of the article) who collected the data was a native

of the study area and had the experience of conducting several studies on women's problems hence he was well acquainted with the characteristic and social customs of the region. So he could obtain the women's consent to participate in the research better and create such an atmosphere for interview that the women could more easily share their information with him.

However, there were some limitations in this study. The first limitation was the lack of familiarity of the women studied with the process of qualitative research and fear of participating in the research. The researchers could attract their attention by explaining the process of interviews and publishing results as well as using a woman researcher familiar with qualitative study. The study was conducted only among women who were married under the age of 18 and were less than 25 years old at the time of interview, so it can be said that the results of our study mostly show the short-term consequences of early marriage. Therefore, it is suggested that further studies be conducted among older women to further reveal the long-term effects and consequences of child marriage. Also, this study was conducted only among one of the Iranian ethnic groups (Kurds) who have a different social and cultural structure than other Iranian ethnic groups, so these results cannot be considered as a complete representation of Iranian society, thus it is suggested that other qualitative studies will be conducted among Other Iranian ethnic groups.

\section{Conclusion}


The results showed that early marriage causes many individual, family and social problems for women that can endanger their health, but in a limited number of cases, early marriage had some positive consequences such as receiving intra-family support, improving living conditions and eventually creating opportunity for progress and empowerment. Therefore in the first stage, early marriage should be prevented, but if it happens, in order to reduce the negative effects and consequences of early marriage, young men and women can be educated and provided with conditions for having a less dangerous pregnancy and childbirth, can have training and psychological counseling on how to deal with personal and married life problems, and can be provided with appropriate health and social services.

\section{Declarations}

\section{Ethics approval and consent to participate}

The study was approved by the Ethics Committee of Iran University of Medical Sciences, with code IR.IUMS.REC.1397.1225. Written consent was obtained from all participants. In addition, written consent was obtained from the spouses of the participants who were under 18 years of age.

\section{Consent to publish}

Not applicable.

\section{Availability of data and materials}

Data are available by contacting the corresponding author.

\section{Competing interests}

All authors declare that they have no competing interests.

\section{Funding}

No funding was received for this work.

\section{Authors' Contributions}

All authors participated and approved the study design. MS, JYL, FEFA and FKF contributed to design the study, collected and analyzed by MS, JYL and FKF. The final report and article were written by MS, JYL, FEFA and FKF . All authors read and approved the final manuscript.

\section{Acknowledgments}

The authors would like to thank all the participants who patiently participated.

\section{Authors' Information}


Professor, Department of Education and Health Promotion, School of Health, Iran University of Medical

Sciences, Tehran, Iran ${ }^{1}$. Professor, Department of Education and Health Promotion, School of Health, Iran University of Medical Sciences, Tehran, Iran² . Associate Prof, Department of Population \& Health, National Population Studies \& Comprehensive Management Institute ${ }^{3}$. PhD Student. Health Education and Health Promotion, School of health, Iran University of Medical Sciences, Tehran, Iran. ${ }^{4}$

\section{References}

1. Tisdall, E.K.M. and P. Cuevas-Parra, Challenges for children's participation: Child activism for ending child marriage. Children and Youth Services Review, 2020. 108: p. 104568.

2. Prakash, R., et al., The Samata intervention to increase secondary school completion and reduce child marriage among adolescent girls: results from a cluster-randomised control trial in India. Journal of global health, 2019. 9(1).

3. Unicef, Ending child marriage: Progress and prospects. 2014: UNICEF.

4. Arthur, M., et al., Child marriage laws around the world: Minimum marriage age, legal exceptions, and gender disparities. Journal of women, politics \& policy, 2018. 39(1): p. 51-74.

5. Schaffnit, S.B., M. Urassa, and D.W. Lawson, "Child marriage" in context: exploring local attitudes towards early marriage in rural Tanzania. Sexual and reproductive health matters, 2019. 27(1): p. 93105.

6. Matlabi, H., et al., Factors responsible for early and forced marriage in Iran. Science Journal of Public Health, 2013. 1(5): p. 227-229.

7. Montazeri, S., et al., Determinants of early marriage from married girls' perspectives in Iranian setting: a qualitative study. Journal of environmental and public health, 2016. 2016.

8. Hajihasani, M. and T. Sim, Marital satisfaction among girls with early marriage in Iran: emotional intelligence and religious orientation. International Journal of Adolescence and Youth, 2019. 24(3): p. 297-306.

9. Pandey, S., Persistent nature of child marriage among women even when it is illegal: The case of Nepal. Children and youth services review, 2017. 73: p. 242-247.

10. Cislaghi, B., et al., Social norms and child marriage in Cameroon: An application of the theory of normative spectrum. Global public health, 2019. 14(10): p. 1479-1494.

11. Hotchkiss, D.R., et al., Risk factors associated with the practice of child marriage among Roma girls in Serbia. BMC international health and human rights, 2016. 16(1): p. 6.

12. Taylor, A.Y., et al., Child marriages and unions in Latin America: Understanding the roles of agency and social norms. Journal of Adolescent Health, 2019. 64(4): p. S45-S51.

13. Kamal, S.M., et al., Child marriage in Bangladesh: trends and determinants. Journal of biosocial Science, 2015. 47(1): p. 120-139.

14. Raj, A., et al., Prevalence of child marriage and its effect on fertility and fertility-control outcomes of young women in India: a cross-sectional, observational study. The lancet, 2009. 373(9678): p. 1883- 
1889.

15. Nasrullah, M., et al., Girl child marriage and its effect on fertility in Pakistan: findings from Pakistan Demographic and Health Survey, 2006-2007. Maternal and child health journal, 2014. 18(3): p. 534543.

16. Irani, M. and R. Latifnejad Roudsari, Reproductive and Sexual Health Consequences of Child Marriage: A Review of literature. Journal of Midwifery and Reproductive Health, 2019. 7(1): p. 15841590.

17. Mardi, A., et al., Factors influencing the use of contraceptives through the lens of teenage women: a qualitative study in Iran. BMC public health, 2018. 18(1): p. 202.

18. Graneheim, U.H. and B. Lundman, Qualitative content analysis in nursing research: concepts, procedures and measures to achieve trustworthiness. Nurse education today, 2004. 24(2): p. 105112.

19. Marshall, M.N., Sampling for qualitative research. Family practice, 1996. 13(6): p. 522-526.

20. Lincoln, Y. and E. Guba, Naturalistic Inquiry London. England. Sage Publications, 1985.

21. Goli, S., A. Rammohan, and D. Singh, The effect of early marriages and early childbearing on women's nutritional status in India. Maternal and child health journal, 2015. 19(8): p. 1864-1880.

22. Ahinkorah, B.O., et al., Examining pregnancy related socio-cultural factors among adolescent girls in the Komenda-Edina-Eguafo-Abrem municipality in the central region of Ghana: a case-control study. Frontiers in public health, 2019. 7: p. 93.

23. Yasmin, G., A. Kumar, and B. Parihar, Teenage pregnancy-its impact on maternal and fetal outcome. International journal of scientific study, 2014. 1(6): p. 9-13.

24. Adhikari, R., K. Soonthorndhada, and P. Prasartkul, Correlates of unintended pregnancy among currently pregnant married women in Nepal. BMC International Health and Human Rights, 2009. 9(1): p. 17.

25. Uecker, J.E., Marriage and mental health among young adults. Journal of Health and Social Behavior, 2012. 53(1): p. 67-83.

26. John, N.A., J. Edmeades, and L. Murithi, Child marriage and psychological well-being in Niger and Ethiopia. BMC Public Health, 2019. 19(1): p. 1029.

27. Daraz, U., A. Naz, and W. Khan, Early Marriage: A Developmental Challenge to Women in Pakhtun Society. FWU Journal of Social Sciences, 2014. 8(1): p. 91.

28. Yoosefi lebni, J., et al., A study of Kurdish women's tragic self-immolation in Iran: A qualitative study. Burns, 2019. 45(7): p. 1715-1722.

29. Gage, A.J., Association of child marriage with suicidal thoughts and attempts among adolescent girls in Ethiopia. Journal of Adolescent Health, 2013. 52(5): p. 654-656.

30. Tenkorang, E.Y., Explaining the links between child marriage and intimate partner violence: Evidence from Ghana. Child abuse \& neglect, 2019. 89: p. 48-57. 
31. Wahi, A., et al., The lived experience of child marriage in the United States. Social work in public health, 2019. 34(3): p. 201-213.

32. Kidman, R., Child marriage and intimate partner violence: a comparative study of 34 countries. International journal of epidemiology, 2017. 46(2): p. 662-675.

33. Tilson, D. and U. Larsen, Divorce in Ethiopia: The impact of early marriage and childlessness. Journal of biosocial science, 2000. 32(3): p. 355-372.

34. Clark, S., Early marriage and HIV risks in sub-Saharan Africa. Studies in family planning, 2004. 35(3): p. $149-160$.

35. Beattie, T.S., et al., Supporting adolescent girls to stay in school, reduce child marriage and reduce entry into sex work as HIV risk prevention in north Karnataka, India: protocol for a cluster randomised controlled trial. BMC Public Health, 2015. 15(1): p. 292.

36. Santhya, K. and S.J. Jejeebhoy, Early marriage and HIV/AIDS: risk factors among young women in India. Economic and Political Weekly, 2007: p. 1291-1297.

37. Paul, P. and P. Chouhan, Association between child marriage and utilization of maternal health care services in India: Evidence from a nationally representative cross-sectional survey. Midwifery, 2019. 75: p. 66-71.

38. Lloyd, C.B. and B.S. Mensch, Marriage and childbirth as factors in dropping out from school: an analysis of DHS data from sub-Saharan Africa. Population Studies, 2008. 62(1): p. 1-13.

39. Delprato, M., et al., On the impact of early marriage on schooling outcomes in Sub-Saharan Africa and South West Asia. International Journal of Educational Development, 2015. 44: p. 42-55. 